\title{
Drivers of knowledge hiding in the university context
}

\author{
Kaiyu Yang, IKI-SEA - Bangkok University, Thailand, karrieyoung@aliyun.com \\ Vincent Ribiere, IKI-SEA - Bangkok University, Thailand, vincent.r@bu.ac.th
}

\begin{abstract}
Knowledge hiding, as an emerging novelty, has started to draw research attention since the last decade or so. Previous literature defined knowledge hiding as one's deliberate attempt to withhold or conceal requested knowledge from another person and contended that three hiding strategies involved are playing dumb, evasive hiding, and rationalized hiding. Previous researchers found that knowledge hiding could be triggered by distrust, characteristics of the requested knowledge, and an intention to adapt to the social context. The purpose of this study was to investigate the reasons and motivations driving individuals to hide their knowledge in an academic context. A sequential mixed-method research design was adopted to help obtain a better understanding of knowledge hiding phenomena. A qualitative study was firstly conducted, which identified three primary independent constructs that may bring about knowledge hiding - interpersonal relationships, personal traits, sustaining personal knowledge advantage. Then the three constructs were further tested with a quantitative study. Results suggested that "personal traits" and "sustaining personal knowledge advantage" constructs significantly influenced knowledge hiding behavior, but the construct of "interpersonal relationships" had no significant influence on our sample's knowledge hiding behavior.
\end{abstract}

Keywords: Knowledge hiding, Knowledge management, Motivations, Academia.

\section{Introduction}

Knowledge hiding, which is found to be a pervasive phenomenon in work settings (Connelly et al., 2012; Labafi, 2017), has started to draw research attention only in the last decade or so. It has been identified as one of the categories of deterrents to knowledge sharing (Qureshi \& Evans, 2015), and a kind of "counterproductive work behaviors" (Bogilović et al., 2017; Serenko \& Bontis, 2016) or knowledge risks (Labafi, 2017). Although knowledge hiding seems to imply opposite meaning to knowledge sharing literally, it does not refer to behavior contrary to the latter, since "a lack of knowledge sharing is likely only driven by an absence of knowledge itself" (Connelly et al., 2012, p. 67).

Increasing research attention has been devoted to knowledge hiding in recent years. Efforts have been made to investigate the definition and the dimensions, the predictors, the outcomes, and the measurements of knowledge hiding in diverse contexts. Nevertheless, a consensus in various aspects is still waiting to be reached. Previous studies have proved that knowledge hiding could be motivated by varying factors, including distrust (Labafi, 2017), reciprocity (Černe et al., 2014), competitive work environment, and lack of confidence (Kumar Jha \& Varkkey, 2018) and the like. 
The purpose of this study was to investigate the reasons and incentives driving individuals to hide their knowledge in the academic context and to determine the extent to which the primary constructs influence knowledge hiding behavior.

\section{Literature Review}

Despite the fact that interchangeable use of "knowledge hiding" and "knowledge withholding" (Bogilović et al., 2017; Černe et al., 2017; Peng et al., 2019) and sometimes "knowledge concealment" (Černe et al., 2014) was commonly found in extant academic studies, it was claimed that the intentional hiding and the unintentional hoarding of knowledge were the two classifications of knowledge withholding (Kang, 2016). Furthermore, knowledge hiding was considered as a kind of counterproductive work behaviors (Bogilović et al., 2017; Serenko \& Bontis, 2016) or knowledge risks (Labafi, 2017). However, Connelly and his colleagues (2012) distinguished knowledge hiding from any other workplace behavior by defining it as "an intentional attempt by an individual to withhold or conceal knowledge that has been requested by another person," (p. 65), which involved three dimensions playing dumb, evasive hiding and rationalized hiding. In the latest studies, new forms of strategies named "counter-questioning" were discovered (Kumar Jha \& Varkkey, 2018). Connelly et al. (2012) asserted that knowledge hiding was a distinctive construct that extended our understanding of knowledge transfer. However, there exists some conceptual overlap between knowledge hiding and these behaviors. Because such behavior does not necessarily involve deception, it may have positive intentions and outcomes rather than harm others (Connelly et al., 2012).

Some efforts in investigating knowledge hiding were made to figure out the antecedents and predictors of such behavior. Interpersonal relationship was found to be playing an essential role in social exchange. Butt and Ahmad (2019) asserted that managers purposely hid knowledge from each other when they lack personal relationships. Good relationships help develop mutual trust and respect, which encourage individuals to share knowledge in work settings. Distrust, on the other hand, is one of the critical reasons for knowledge hiding in organizations (Labafi, 2017). Distrust showed by the knowledge hider and sensed by the requester generates a reciprocal loop that will intensify knowledge hiding behavior and then will damage the person who hid knowledge from their coworkers in the first place (Černe et al., 2014). Psychology of ownership refers to the feeling that one is being psychologically tied to an object (Aljawarneh \& Atan, 2018). Aljawarneh and Atan (2018) theorized that employees might conduct knowledge hiding behaviors for they believed that they own the knowledge, lack trust in their colleagues, and have a sense of belonging. Besides, it was proved that the perception of organizational politics positively predicted knowledge hiding (Malik et al., 2019) and that proving goal orientation increased knowledge hiding (Rhee \& Choi, 2017). Additionally, behavioral characteristics, the complexity of knowledge, the power of requesting person, as well as organizational incentives for knowledge sharing were also found to be the predictors of knowledge hiding (Labafi, 2017). Furthermore, competitive work environment, perceived career insecurity, lack of recognition, lack of reciprocation, and lack of confidence in one's knowledge were proved to be the triggers of knowledge hiding (Kumar Jha \& Varkkey, 2018). 
When it comes to the outcomes of knowledge hiding, it was stated that knowledge hiding was not always harmful (Labafi, 2017; Xiao \& Cooke, 2019). Employees sometimes hide knowledge to protect the organization or their self-interest (Xiao \& Cooke, 2019). Furthermore, secrecy could strengthen rather than damage organizations when it was analyzed as a social fabric of interactions around workplace and shared feelings triggered by the risks of working in secret because it transformed team members' perception of time, and it reinforced their exchange (Courpasson \& Younes, 2018). Connelly and Zweig (2015) suggested that not all knowledge hiding, in terms of the three dimensions, was equally harmful. For example, rationalized hiding could enhance interpersonal relationships between the person who was requested and the one who made the request. Further investigation of the influence of different attributes of knowledge hiding on team creativity showed that evasive hiding and playing dumb significantly and negatively influenced team creativity, while rationalized hiding did not significantly impact on team creativity (Bari et al., 2019).

The existing researches cover a broad range of industries and fields. Samples from manufacturing and processing industry (Černe et al., 2014; Černe et al., 2017; Peng et al., 2019), informational technology (Peng et al., 2019), high-technology organizations (Courpasson \& Younes, 2018; Fong et al., 2018), software industry (Labafi, 2017), hospitality industry (Aljawarneh \& Atan, 2018), and higher education/academia (Demirkasimoglu, 2016; Hernaus et al., 2019) have been investigated. It can be found that higher education/academia and high technology organizations caught more attention concerning this research topic. The reason could be that individuals involved in these fields, compared with employees in others, are placed with higher expectations to generate creative ideas or bring forth innovation. In the context of academia, previous results of knowledge hiding researches suggested that respondents' positive attitudes and good intentions towards knowledge sharing might have a relation to their belief that knowledge sharing would advance and extend their relationships with coworkers, and bring opportunities for promotion in the organization and appointments outside the organization (Fullwood et al., 2013). Besides, it was proved that academics hid more tacit than explicit knowledge (Hernaus et al., 2019). Research aiming to analyze the knowledge hiding types of academicians and their relationship between personality traits found that different personality has a different relationship to the three knowledge hiding strategies (Demirkasimoglu, 2016). Thus, the objective of this study is to inquire into the motivations and drivers of knowledge hiding among academics. We believe that by digging into individuals' motivation of hiding knowledge, hopefully, effective means and measures of creating a climate that encourages knowledge sharing and decreases less knowledge hiding can be discovered.

\section{Research Methodology}

An exploratory sequential mixed-method research design was used to help achieve a better understanding of the knowledge hiding phenomena. Qualitative data was first collected from faculties of a foreign language department of a Chinese university through interviews, and secondly, a survey was used to further explore the initial findings. 


\section{Qualitative Data Collection and Analysis}

For this study, five interviews (Table 1) were conducted to collect data that were then adequately interpreted and analyzed. The participants who took part in this study are academics of a foreign language department from a Chinese university. They are all fluent in English. Out of the five participants, four are female, and one is male, working experience ranging from almost one year to 16 years. In terms of education, one of the respondents obtained a bachelor's degree, three master's, and one Ph.D.'s. All of the five are involved in teaching work, while two also work as a director, and one is in a management position in the department, working as vice dean. The time duration of interviews is between 44 minutes to 59 minutes. Table 1 shows the demographics of the respondents. Each interview was conducted face to face in English. All interviews were audiorecorded under the interviewees' consent and then transcribed verbatim.

Table 1. Demographics of Interviewees

\begin{tabular}{|c|c|c|c|c|c|}
\hline ID & Gender & $\begin{array}{c}\text { Working experience } \\
\text { (years) }\end{array}$ & Degree & Position & $\begin{array}{c}\text { Time of interview } \\
\text { (appx. minutes) }\end{array}$ \\
\hline 1 & F & 16 & Bachelor's & Director & 45 \\
\hline 2 & F & 3 & Master's & Faculty & 59 \\
\hline 3 & F & 7 & Ph.D.'s & Vice-dean & 53 \\
\hline 4 & F & 15 & Master's & Faculty & 47 \\
\hline 5 & M & 1 & Master's & Director & 44 \\
\hline
\end{tabular}

In this study, respondents were requested to recall the latest incidents, in one of which the respondents hid knowledge from their colleagues, and in another, their colleagues hid from them. They were then asked to specify the motivation after describing each incident. Also, during the interview, the participants were required to answer some questions regarding the type of hidden knowledge, department climate, which were proved by previous researches to influence knowledge hiding behavior, and strategies used to hide knowledge. A thematic analysis was conducted to analyze the verbatim transcripts using the software MaxQDA.

\section{Findings}

It was generally believed among the interviewees that although their working climate did not encourage knowledge hiding, such behavior did happen in work settings. Based on the data that have been collected, we reached a certain level of saturation regarding respondents' answers and eventually extracted out three primary factors influencing individuals' decision to hide knowledge through a thematic analysis.

\section{Interpersonal Relationship}

Interpersonal relationship is found to be one of the crucial factors motivating knowledge hiding behavior in our qualitative study. It was believed that distrust brought about individuals' knowledge hiding. Individuals were found to have tended to hide their knowledge from those whom they did not trust. When being asked to specify why the participant's colleague hid knowledge from her, one interviewee stated,

"He cannot trust me. Moreover, I'm not the person on her side ... I'm not the right person."

Another thought she and the colleague who turned her request down were "not close enough", and claimed that 
"I would hide knowledge from people whom I don't know very well."

Previous studies have found a strong relationship between norms of reciprocity to knowledge sharing intention (Tamjidyamcholo et al., 2013). While our interviewees' reports showed that, in some cases, lack of reciprocity generated knowledge hiding:

"Maybe they think that I did not devote enough for them before."

"People's relationship can help them to understand each other better, and maybe I thought this person is my good friend, but maybe in her or his position, I'm not his good friend."

And the interviewee hid knowledge from colleagues because

"The colleagues there made me feel unhappy when I was leaving" ... "I think they don't deserve my knowledge sharing."

\section{Personal traits}

Although participants in our interviews thought that knowledge hiding was omnipresent in their work settings, some of them claimed that it was understandable for colleagues to hide their knowledge from one another and that they would not hide knowledge from colleagues even though they knew that the others were hiding from him/her.

"Because sometimes I will hide something myself ... So, I think I can understand."

"I'd love to share anything I know with others" ... "there's nothing to hide."

"Actually, most of the time, I don't hide knowledge because if somebody asks me, I just tell them, and I like to share."

"I think I would like to share because if it is not necessary for me to keep a secret, then I think it's not a problem to share. I mean knowledge, actually, most knowledge is to be shared."

In our interviews, it was found that people would like to hide their knowledge from colleagues due to a lack of self-confidence both in work in progress and tacit knowledge. In order to avoid being embarrassed, respondents chose to hide what they were working on or ideas they considered of less significance.

"If I am working on something, I don't want them to know my progress" ... "I think he may think I am too slow or something, cause I'm usually very slow."

"I'm not confident that my tacit knowledge is correct or not ..."

"Because sometimes I'm not certain about what I know, what I want to do, yes. So, I just feel shy to share."

"I think I would be embarrassed. Because I don't have a lot of knowledge about this idea, I think it would make me embarrassed if I, you know, can't get it right."

"I just think that my knowledge is not so precious to be kept by myself."

"I think she ... she maybe thinks her product is not good enough." 
The competitive situation is another prominent generator of knowledge hiding behavior according to the participants in this study. Feelings for competition in a teaching contest in the university context, for example, would trigger knowledge hiding between colleagues.

"I think because we are opponents at that time. So, I think it's reasonable that she wants to be outstanding."

"I just suppose I am going to have a competition, maybe I need to hide something." hiding."

“... competitive relationship between colleagues. So, I think that may encourage knowledge

“...they didn't want me to be better."

\section{Sustaining personal knowledge advantage}

Being afraid of losing one's unique value and power base in work settings, some individuals conducted knowledge hiding behavior to ensure their knowledge advantage sustainable.

"Maybe people want to keep their academic competitiveness."

"Because if when you are in the same competition, of course, you will have to keep your own advantage. So, I think that's the reason."

"We are in a competitive relationship, so if I get to know their experiences to do something, they may think someday I will replace them."

“... to keep something ... some knowledge to be their own ... to be special."

The uniqueness of knowledge gave rise to knowledge hiding between colleagues in the university context. When talking about research and teaching material, interviewees stated,

"... they have their data. Because they don't ... maybe they don't want other people to know how did they get their data and how to analyze the data and something."

“... they think it's their work, they don't want to share, just hide it."

"to keep their ideas unique and to keep their ideas, maybe I should say, from being stolen."

Individuals were found more likely to hide tacit knowledge than explicit knowledge in our study. Experience related to a particular job, research ideas, a research topic that is considered to be creative by the interviewee was the knowledge they would like to hide from colleagues. Answers to the questions "if your colleagues hide knowledge from the others, what kind of knowledge do they hide" are as follows:

"Tacit, it's the tacit knowledge."

"Maybe their unique idea or research, maybe something they are not sure ......new concept or a new focus."

One interviewee mentioned that she hid her knowledge from colleagues because of worries of time consumption,

"Because even I share, they don't know how to do it. I have to do the work for them" ... "I don't want to share how to do it step by step." 
In addition to the three dominant categories, some other findings drew our attention during the interviews. For instance, one interviewee reported that affect had an influence on his decision to hide knowledge or not.

"I think when I don't feel that good, like emotionally... today I'm not happy, and I may not ...it has nothing to do with the environment or with relationships. Just depend ... If they ...ask me too much, I may get bored..."

While another took confidentiality of knowledge into consideration when facing the dilemma of whether to hide knowledge or not.

"Maybe it's related to some secret or important information we cannot open to others."

\section{Positive aspects of knowledge hiding}

One more interesting finding is that knowledge hiding behavior could be the result of goodwill rather than evil intention. For example, people might hide knowledge to help others to develop their own knowledge, which was found to be the characteristic of a leader's knowledge hiding behavior.

"I told our secretary to do something, but I just told them what they had to do, but I didn't tell the details and how to do it" ... "they have to learn how to write a summary right."

Some considered hiding "negative news" from their colleagues to protect their feelings.

"Some information I don't want to know. If I know, how to say, the information may make me sad, or it's not good for me."

Furthermore, it was reported that knowledge hiding might result in positive consequences, which is different from the general belief that it only brings about negative outcomes. For example,

"Knowledge hiding forces a person to work on his or her own job, to find the solution."

We believe that the differences between leader's and subordinates' motivation for hiding knowledge and the bright side of knowledge hiding deserve more research attention.

\section{Quantitative Data Analysis}

In order to further explore our initial findings, we decided to conduct quantitative data analysis using a survey method. Based on the qualitative study findings, three main independent constructs- interpersonal relationships, personal traits, sustaining personal knowledge advantage -- were highlighted as the main constructs in our study. Eight variables, which were extracted from coding of the interviews in our qualitative study, were used to measure the three independent constructs. This resulted in the development of a conceptual model (Figure 1). Three main research hypotheses were stated:

$\mathrm{H}_{1}$ : Interpersonal relationships (Distrust, Lack of reciprocity) has a positive influence on Knowledge Hiding behaviors

$\mathrm{H}_{2}$ : Personal traits (Selfishness, Lack of confidence, Feelings for competition) have a positive influence on Knowledge Hiding behaviors 
$\mathrm{H}_{3}$ : Sustaining personal knowledge advantage (Benefit cost, Loss of Knowledge power, Knowledge complexity) has a positive influence on Knowledge Hiding behaviors

The definitions of all the variables used on our conceptual model can be found in Table 2 .

Table 2. Operational Definitions and Referential Sources of Research Variables.

\begin{tabular}{|c|c|c|}
\hline Variables & Operational definitions & Sources \\
\hline \multirow[b]{2}{*}{ Distrust } & $\begin{array}{l}\text { Distrust the intention of "not willing to depend or intends not to depend, on } \\
\text { the other party, with a feeling of relative certainty or confidence, even though } \\
\text { negative consequences are possible" }\end{array}$ & $\begin{array}{l}\text { McKnight \& } \\
\text { Chervany, 2001, p. } \\
43\end{array}$ \\
\hline & $\begin{array}{l}\text { Malevolence the belief in the bad intentions and ill will of another toward } \\
\text { you } \\
\text { Incompetence the belief that another is inept to do as they claim they will do } \\
\text { Deceit the belief in the dishonesty and duplicity of another }\end{array}$ & Rusk, 2018, p. 84 \\
\hline $\begin{array}{l}\text { Lack of } \\
\text { Reciprocity }\end{array}$ & $\begin{array}{l}\text { Inequality "of one's perceived investments in and benefits from an exchange } \\
\text { relationship, relative to the person's own internal standards regarding this } \\
\text { relationship" }\end{array}$ & Schaufeli, 2006, p. 81 \\
\hline Selfishness & $\begin{array}{l}\text { Selfishness concerned excessively or exclusively with oneself: seeking or } \\
\text { concentrating on one's own advantage, pleasure, or well-being without regard } \\
\text { for others } \\
\text { Egocentric Selfishness "selfishness with a single-minded attentional focus } \\
\text { on the self" } \\
\text { Adaptive Selfishness "a 'softer' form of selfish behavior with an eye to } \\
\text { others" } \\
\text { Pathological Selfishness "a form of 'hard' selfishness in which others are } \\
\text { harmed for self advancement" }\end{array}$ & $\begin{array}{l}\text { Raine \& Uh, 2019, } \\
\text { pp. 503- } 504\end{array}$ \\
\hline $\begin{array}{l}\text { Lack of self- } \\
\text { confidence }\end{array}$ & $\begin{array}{l}\text { "Self-confidence is a person's belief that he or she can succeed. Self- } \\
\text { confidence is context-specific to particular tasks and some people seem to } \\
\text { display this characteristic through a wide range of activities. Self-confidence } \\
\text { can be related to self-efficacy theory." }\end{array}$ & Perry, 2011, p. 219 \\
\hline $\begin{array}{l}\text { Feelings for } \\
\text { competition }\end{array}$ & $\begin{array}{l}\text { Competition "the act of seeking or endeavoring to gain what another is } \\
\text { endeavoring to gain at the same time" }\end{array}$ & $\begin{array}{l}\text { Lu et al., 2013, p. } \\
1137\end{array}$ \\
\hline Benefit Cost & $\begin{array}{l}\text { Benefit an advantage, value preserved from hiding knowledge. } \\
\text { Cost loss of value derived from sharing knowledge (indirect potential } \\
\text { implication) }\end{array}$ & $\begin{array}{l}\text { Lin et al., 2012, p. } \\
757\end{array}$ \\
\hline $\begin{array}{l}\text { Loss of } \\
\text { knowledge } \\
\text { power }\end{array}$ & $\begin{array}{l}\text { Reduction in employee uniqueness, which in turn, increase their } \\
\text { sustainability and reduces their (knowledge) power }\end{array}$ & Gray, 2001, p. 380 \\
\hline $\begin{array}{l}\text { Knowledge } \\
\text { complexity }\end{array}$ & $\begin{array}{l}\text { The difficulty degree to acquire and disseminate knowledge (often of tacit } \\
\text { nature) }\end{array}$ & Kou, 2002, p. 57 \\
\hline $\begin{array}{l}\text { Knowledge } \\
\text { Hiding }\end{array}$ & $\begin{array}{l}\text { Knowledge Hiding is "an intentional attempt by an individual to withhold } \\
\text { or conceal knowledge that has been requested by another person" } \\
\text { Evasive hiding "involves instances where the hider provides incorrect } \\
\text { information or a misleading promise of a complete answer in the future, even } \\
\text { though there is no intention to actually provide this" } \\
\text { Playing dumb "describes behaviors whereby the hider pretends to be } \\
\text { ignorant of the relevant knowledge" } \\
\text { Rationalized hiding "the hider offering a justification for failing to provide } \\
\text { requested knowledge by either suggesting he or she is unable to provide the } \\
\text { knowledge requested or by blaming another party" }\end{array}$ & $\begin{array}{l}\text { Connelly et al., } 2012 \text {, } \\
\text { pp. } 65,75,76\end{array}$ \\
\hline
\end{tabular}

For each variable, we identified and relied on some pre-existing survey instruments, from which the validity and reliability have been tested. Table 3 indicates the number of items that were used 
to measure each variable. For our knowledge hiding dependent variable, we used Connelly et al. (2012)'s 12-item scales, which is popularly adopted by researchers (Černe et al., 2014; Fong et al., 2018; Peng et al., 2019) to measure individual's knowledge hiding behavior. Three dimensions are included in the scale: evasive hiding, playing dumb and rationalized hiding. Each dimension consists of four items. It turns out that this measurement is with high internal reliability, with Cronbach's Alpha values in these studies are around 0.80 .

To provide some demographics about the respondents, $67 \%$ were female and $33 \%$ male, $46 \%$ had more than 21 years of experience, 9\% 16-20 years, 18\% $11-15$ years, $12 \% 6-10$ years, and 15\% 15 years. In terms of education: $24 \%$ had a Ph.D., $40 \%$ a Master's degree, and 36\% a Bachelor's degree. Finally, in terms of academic position: $88 \%$ were faculty, $9 \%$ were Dean/Vice Dean, and $3 \%$ were Directors.

The link to the online survey (in English) was sent to all 50 faculties of the foreign language department of the same Chinese university. Thirty-three faculties filled up the survey $(66 \%$ response rate). The survey took an average of 20 minutes to be completed. In order to re-test the reliability of the scales that we borrowed from previously tested measurement instruments, we ran a Cronbach's Alpha test on all the variables of our three main constructs. Table 3 presents the results of the Cronbach's Alpha tests. Of our eight variables, three showed "acceptable" reliability, with Cronbach alpha values between 0.7 and 0.79 , four were "good", with the values between 0.8 and 0.9 , and one was "excellent", with the value over 0.9. Moreover, the values of the three main constructs were all above 0.70 , which proved that the scales we used in this study were reliable.

Table 3. Scales Reliability Testing

\begin{tabular}{|l|l|c|c|}
\hline \multicolumn{1}{|c|}{ Construct } & \multicolumn{1}{|c|}{ Variables } & Number of items & Cronbach's Alpha \\
\hline \multirow{3}{*}{$\begin{array}{l}\text { Interpersonal } \\
\text { Relationships }\end{array}$} & $($ All) & 12 & 0.862 \\
\cline { 2 - 4 } & Distrust & 9 & 0.821 \\
\cline { 2 - 4 } & Lack of reciprocity & 3 & 0.710 \\
\hline \multirow{4}{*}{ Personal Traits } & $($ All) & 14 & 0.794 \\
\cline { 2 - 4 } & Selfishness & 9 & 0.712 \\
\cline { 2 - 4 } & $\begin{array}{l}\text { Feelings for competition } \\
\text { (affect) }\end{array}$ & 2 & 0.719 \\
\cline { 2 - 4 } & Lack of self-confidence & 3 & 0.824 \\
\hline \multirow{2}{*}{$\begin{array}{l}\text { Sustaining } \\
\text { personal } \\
\text { knowledge } \\
\text { advantage }\end{array}$} & (All) & 15 & 0.924 \\
\cline { 2 - 4 } & Benefit (cost) & 4 & 0.860 \\
\cline { 2 - 4 } & Loss of Knowledge power & 4 & 0.919 \\
\cline { 2 - 4 } & Knowledge complexity & 4 & 0.815 \\
\hline
\end{tabular}

Table 4 provides some descriptive statistics about the variables of our model. The Likert scale used ranged from 1 to 5 (Disagree (1) to Agree (5)). 
Table 4. Descriptive Statistics of Model Variables

\begin{tabular}{|l|l|r|r|r|r|}
\hline & $\mathrm{N}$ & \multicolumn{1}{|c|}{ Minimum } & \multicolumn{1}{c|}{ Maximum } & \multicolumn{1}{c|}{ Mean } & Std. Deviation \\
\hline Interpersonal_Relationships & 33 & 1.00 & 4.15 & 2.4942 & 0.77713 \\
Distrust & 33 & 1.00 & 4.33 & 2.4747 & 0.79216 \\
Lack_of_Reciprocity & 33 & 1.00 & 5.00 & 2.4444 & 1.01607 \\
Personal_traits & 33 & 1.14 & 4.00 & 2.3615 & 0.70754 \\
Selfishness & 33 & 1.11 & 4.11 & 2.4512 & 0.74065 \\
Feelings_for_competition & 33 & 1.00 & 5.00 & 2.2576 & 1.21270 \\
Lack_of_self_confidence & 33 & 1.00 & 5.00 & 2.1616 & 1.18767 \\
Knowledge_Advantage & 33 & 1.00 & 4.73 & 2.2314 & 1.08547 \\
Benefit_Cost & 33 & 1.00 & 5.00 & 2.4242 & 1.24763 \\
Loss_of_Knowledge_Power & 33 & 1.00 & 5.00 & 2.0606 & 1.21519 \\
Complexity & 33 & 1.00 & 4.25 & 2.1288 & 1.01766 \\
Knowledge_Hiding & 33 & 1.00 & 4.50 & 2.2273 & 0.89347 \\
Evasive_Hiding & 33 & 1.00 & 4.75 & 2.0985 & 1.11967 \\
Playing_Dumb & 33 & 1.00 & 4.25 & 2.2424 & 0.99508 \\
Rationalized_Hiding & 33 & 1.00 & 4.75 & 2.3409 & 1.05478 \\
Valid N (listwise) & 33 & & & & \\
\hline
\end{tabular}

In order to test our conceptual model, we conducted a Multiple linear regression analysis. The results of the multiple regression are presented in Table 5. In this study, knowledge hiding was taken as a single dependent variable, which was in consistence with some previous studies (e.g., Černe et al. (2014)), in which the mean of knowledge hiding variable had been the average of the three strategies'.

Table 5. Regression Analysis Results

\begin{tabular}{|l|c|r|r|r|}
\hline & \multicolumn{4}{|c|}{ Model Summary } \\
Model & R & \multicolumn{1}{|c|}{ R Square } & $\begin{array}{r}\text { Adjusted } \\
\text { R Square }\end{array}$ & \multicolumn{2}{|c|}{ Std. Error of the Estimate } \\
\hline 1 & $0.738^{\mathrm{a}}$ & 0.545 & 0.498 & 0.63312 \\
\hline
\end{tabular}

a. Predictors: (Constant), Personal_traits, Interpersonal_Relationships, Knowlegde_Advantage

ANOVA

\begin{tabular}{|c|c|c|c|c|c|c|}
\hline & & $\begin{array}{l}\text { Sum of } \\
\text { Squares }\end{array}$ & df & Mean Square & $\mathrm{F}$ & Sig. \\
\hline \multirow[t]{3}{*}{1} & Regression & 13.921 & 3 & \multirow{3}{*}{$\begin{array}{l}4.640 \\
0.401\end{array}$} & \multirow[t]{3}{*}{11.577} & \multirow[t]{3}{*}{$0.000^{\mathrm{b}} * * *$} \\
\hline & Residual & 11.624 & 29 & & & \\
\hline & Total & 25.545 & 32 & & & \\
\hline
\end{tabular}

a. Dependent Variable: Knowledge Hiding

b. Predictors: (Constant), Personal_traits, Interpersonal_Relationships, Knowlegde_Advantage

*** $p<0.001$ 
Table 6. Regression Analysis Results (Cont.)

\begin{tabular}{|c|c|c|c|c|c|c|c|c|c|}
\hline \multirow[b]{3}{*}{ Model } & \multicolumn{7}{|c|}{ Coefficients } & \multirow{2}{*}{\multicolumn{2}{|c|}{$\begin{array}{c}\text { Collinearity } \\
\text { Statistics } \\
\end{array}$}} \\
\hline & \multicolumn{2}{|c|}{$\begin{array}{l}\text { Unstandardize } \\
\text { d Coefficients }\end{array}$} & 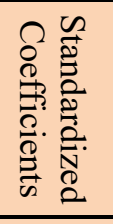 & $\mathrm{t}$ & Sig. & \multicolumn{2}{|c|}{$\begin{array}{c}95.0 \% \\
\text { Confidence } \\
\text { Interval for B }\end{array}$} & & \\
\hline & $\mathrm{B}$ & $\begin{array}{l}\text { Std. } \\
\text { Error }\end{array}$ & Beta & & & $\begin{array}{l}\text { Lower } \\
\text { Bound }\end{array}$ & $\begin{array}{l}\text { Upper } \\
\text { Bound }\end{array}$ & Tolerance & VIF \\
\hline 1 (Constant) & 0.406 & 0.452 & & 0.898 & 0.377 & -0.518 & 1.330 & & \\
\hline Interpersonal_Relationships & -0.069 & 0.219 & -0.060 & -0.314 & 0.756 & -0.516 & 0.378 & .434 & 2.302 \\
\hline Knowledge_advantage & 0.367 & 0.176 & 0.446 & 2.080 & $0.046 *$ & 0.006 & 0.728 & .342 & 2.927 \\
\hline Personal_trait & 0.497 & 0.238 & 0.394 & 2.088 & $0.046^{*}$ & 0.010 & 0.984 & .441 & 2.266 \\
\hline
\end{tabular}

a. Dependent Variable: Knowledge_Hiding

$* p<0.05$

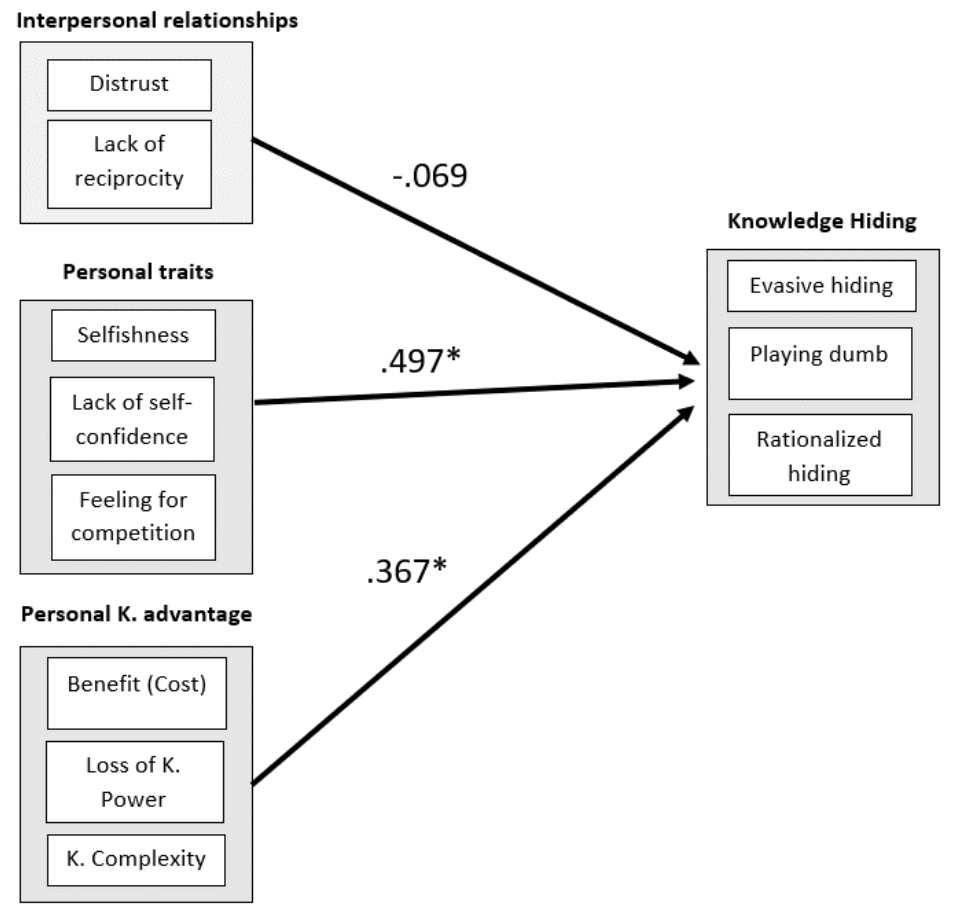

Figure 1. Results of Multiple Regression Analysis

In order to get a better level of understanding, we tested independently, for each of our three constructs, how each of their composing variables correlated with Knowledge Hiding. This test was performed by conducting another set of multiple regressions. For the Interpersonal relationships construct, the Lack of reciprocity variable was significant $(\mathrm{p}=0.019)$ with $(\beta=0.447)$, the Distrust variable being non-significant $(\mathrm{p}=0.727)(\beta=0.082)$. For the Personal traits construct, the Selfishness variable was significant $(p=0.001)$ with $(\beta=0.649)$, the Lack of self-confidence variable was significant $(\mathrm{p}=0.04)$ with $(\beta=0.210)$ and the Feelings for competition variable being 
non-significant $(p=0.783)(\beta=-0.028)$. For the Sustaining personal knowledge, advantage construct, the Benefit cost variable was significant $(\mathrm{p}=0.008)$ with $(\beta=0.470)$, the Knowledge complexity variable was non-significant $(\mathrm{p}=0.280)$ with $(\beta=0.178)$ and the Loss of knowledge power variable being non-significant $(p=0.655)(\beta=-0.067)$.

A post-hoc analysis was performed using an independent sample t-test and a series of One-way Analysis of Variance (ANOVA) analysis to check if there were any differences between individuals' gender, work experience, rank, degree, and position and their knowledge hiding strategies. Results revealed that significant differences existed between males and females for the distrust variable where women were more likely to distrust colleagues $(\mu=2.74)$ than men $(\mu=$ 1.94) $(\mathrm{p}=0.004)$. For the Interpersonal relationships construct women $(\mu=2.74)$ men $(\mu=2.00)$, $(\mathrm{p}=0.009)$. Finally, women $(\mu=2.33)$ were significantly more likely to use the Evasive hiding strategy than men $(\mu=1.64)(\mathrm{p}=0.045)$.

\section{Results}

The findings of our qualitative analysis drove us to develop a conceptual framework to test to which extent our three main constructs could be good predictors of knowledge hiding behavior in this specific faculty environment. If we first look at Table 7, we can see that the most commonly used knowledge hiding behavior for our sample is "I said that I was not very knowledgeable about the topic", which is one of the "Playing dumb" knowledge hiding strategy.

Table 7. Score of Each Type of Knowledge Hiding Behavior

\begin{tabular}{|l|l|l|}
\hline Knowledge Hiding Questions & Mean & Knowledge Hiding type \\
\hline I said that I was not very knowledgeable about the topic. & 2.94 & Playing dumb \\
\hline $\begin{array}{l}\text { I explained that the information is confidential and only available to people } \\
\text { on a particular project. }\end{array}$ & 2.64 & Rationalized hiding \\
\hline I explained that I would like to tell him/her, but was not supposed to. & 2.48 & Rationalized hiding \\
\hline I told him/her that my boss would not let anyone share this knowledge. & 2.48 & Rationalized hiding \\
\hline I agreed to help him/her but never really intended to. & 2.30 & Evasive hiding \\
\hline $\begin{array}{l}\text { I agreed to help him/her but instead gave him/her information different from } \\
\text { what s/he wanted. }\end{array}$ & 2.18 & Evasive hiding \\
\hline $\begin{array}{l}\text { I told him/her that I would help him/her out later but stalled as much as } \\
\text { possible. }\end{array}$ & 2.15 & Evasive hiding \\
\hline I said that I did not know, even though I did. & 2.15 & Playing dumb \\
\hline I pretended that I did not know the information. & 1.97 & Playing dumb \\
\hline I pretended I did not know what s/he was talking about. & 1.91 & Playing dumb \\
\hline $\begin{array}{l}\text { I offered him/her some other information instead of what he/she really } \\
\text { wanted. }\end{array}$ & 1.76 & Evasive hiding \\
\hline I said that I would not answer his/her questions. & 1.76 & Rationalized hiding \\
\hline
\end{tabular}


Based on the interviews we conducted, the reason behind the choice of playing dumb might be that faculty do not want to alter their relationships with their peers, and consequently, such an approach might fit this goal. Nevertheless, "Rationalized hiding" practices are, on average, more frequently used (2.34) than "Playing dumb" (2.24) and "Evasive hiding" (2.10) strategies. Using rationalized hiding strategy is a way to justify the reason behind hiding knowledge through a policy/organizational reason. So it is not that the knowledge hider is not willing to share his/her knowledge, but he/she is not allowed to do so because of a third party. Nevertheless, one of the rationalized hiding behavior, "I said that I would not answer his/her questions" (rationalized hiding) was the least used behavior to hide knowledge since it might generate conflict and alter the relationship between colleagues.

The result of our conceptual model testing showed that the "personal traits" and the "sustaining personal knowledge advantage" were the only two constructs that significantly influenced knowledge hiding behavior (Hypotheses \#2 \& \#3 are validated) but the "interpersonal traits" construct had no significant influence on our sample's knowledge hiding behavior (we failed to validate Hypothesis \#1). If we look at the individual variables composing each construct, even though "Interpersonal relationships" was not significant, the "Lack of reciprocity" variable showed some significantly positive influence on knowledge hiding behavior. For the "Personal traits" construct, the most influential construct, "Selfishness" and "Lack of self-confidence" variables demonstrated to have the most positive influence on knowledge hiding behavior. Finally, for the "Sustaining personal knowledge advantage" construct, the "Benefit cost" and the "Knowledge Complexity" variables significantly positively influenced knowledge hiding behaviors.

What does it tell us? First of all, that faculty first consider their own interests rather than the social/interpersonal ones to decide on hiding knowledge or not. Some degree of selfishness behaviors can explain knowledge hiding but it is also often because faculty are not so secure/selfconfident about what they know and consequently they may rather hide their knowledge rather than saying something not completely right that could make them lose face among their peers.

"I think I would be embarrassed. Because I don't have a lot of knowledge about this idea, I think it would make me embarrassed if I, you know, can't get it right."

When it comes to sustaining personal knowledge advantage, what they can gain/lose by hiding knowledge is an essential part of their decision factor but once again, the hiding reason might also be that what they know is not so easy to disseminate (tacit/experiential knowledge) and that sharing it with colleagues might require a lot of time and efforts and their current workload/free time might not give them such opportunity. So they better hide what they know rather than having to spend a lot of time explaining it to others.

"Because even I share, they don't know how to do it. I have to do the work for them" ... "I don't want to share how to do it step by step."

Finally, as part of the personal traits construct, lack of reciprocity had an impact on faculty decision to hide or not their knowledge. Faculty are more likely to hide their knowledge when they perceive an imbalance between their knowledge contribution and what they get in return. 
"Maybe they think that I did not devote enough for them before."

In addition, differences between males and females in the distrust variable and Interpersonal relationships construct might indicate that compared with males, females embrace more uncertainty about their colleagues and have more problems in trust issue and that they hold more negative attitudes when it comes to their relationships with their colleagues. It might be because females attach more importance to interpersonal relationships and are more mentally involved in interpersonal interactions. The same reasons can also be used to explain why females were more likely to adopt evasive hiding strategy than males do. Evasive hiding strategy might be more likely to help prevent them from losing colleagues' trust and maintain positive relationships with their colleagues.

\section{Conclusion}

This mixed-method research is an initial investigation of factors that lead to knowledge hiding in an academic context. Both Qualitative and Quantitative data collections revealed some interesting findings (previously described) that will be worth further investigating on a larger scale and in different contexts. The main takeaway from this research is that faculties not only hide knowledge because they are selfish, or in order to sustain a personal knowledge advantage or to be more competitive, it might be just because they are not self-confident of what they know, or because they are not "allowed" to share it, or because it requires a lot of efforts to share their knowledge and they don't have this resource. In a collectivist culture like China, where people are by nature more inclined to favor the group benefit rather than their personal benefit, it is interesting to see that Chinese academics also have a tendency to behave like their western counterparts, where knowledge sharing with students is a given, but where limited knowledge sharing and knowledge hiding with their peers is a common practice! We believe that the research opportunity in crossculture investigations into knowledge hiding behavior is worth grasping and that such investigations will lead to one of the most fruitful research avenues under the topic of interest.

Our recommendations in order to limit the negative effects of knowledge hiding, will be to develop a culture where people are encouraged/recognized/rewarded for not hiding their complex(tacit) knowledge and where making mistakes is also perceived as a learning/development process rather than an activity that might lead for them to lose face, moving from a "Knowledge is power" mentality to a "Knowledge sharing is power" mentality.

We would like to end this paper with what we found to be an interesting reason for hiding knowledge, given by a senior faculty and admin person. "Sometimes I partially hide knowledge from my staff because I want them to learn on their own and self develop such kind of knowledge, rather than directly giving it to them", so in certain circumstances, knowledge hiding can have some positive impact too.

As far as the limitations of this initial research, the interview part was limited, only five interviews were conducted. In terms of the quantitative part, for sure the size of our sample was quite limited $(n=33)$ and it will be valuable to obtain data from a larger sample size, including other university departments, and collecting data from other universities and from different countries to check if the reasons behind knowledge hiding are similar. Moreover, as it was claimed by Connelly et al. (2012) that knowledge hiding is a prevalent phenomenon in work settings, it would help us unveil 
this mixed-motive human behavior if future researches are to be conducted in various industries. In this study, we found out that there existed differences between male and female in some independent variables and one knowledge hiding strategy -- evasive hiding, which, we believe, deserves a close look in future studies. We suggest that future studies look into behavioral differences for interactions between female-female, female-male, or male-female, to examine if individuals behave differently when requested by others in different genders, and check if the relationships between independent variables and different knowledge hiding strategies are all the same, since "playing dumb" and "evasive hiding" strategies involved some deception while rationalized hiding involved no deception (Connelly et al., 2012).

\section{References}

Aljawarneh, N. M. S., \& Atan, T. (2018). Linking tolerance to workplace incivility, service innovative, knowledge hiding, and job search behavior: The mediating role of employee cynicism. Negotiation and Conflict Management Research, 11(4), 298-320. https://doi.org/10.1111/ncmr.12136

Bari, M. W., Abrar, M., Shaheen, S., Bashir, M., \& Fanchen, M. (2019). Knowledge hiding behaviors and team creativity: The contingent role of perceived mastery motivational climate. SAGE Open, 9(3), 1-15. https://doi.org/10.1177/2158244019876297

Bogilović, S., Černe, M., \& Škerlavaj, M. (2017). Hiding behind a mask? Cultural intelligence, knowledge hiding, and individual and team creativity. European Journal of Work \& Organizational Psychology, 26(5), 710-723. https://doi.org/10.1080/1359432X.2017. 1337747

Butt, A. S., \& Ahmad, A. B. (2019). Are there any antecedents of top-down knowledge hiding in firms? Evidence from the United Arab Emirates. Journal of Knowledge Management, 23(8), 1605-1627. https://doi.org/10.1108/JKM-04-2019-0204

Černe, M., Nerstad, C. G. L., Dysvik, A., \& Škerlavaj, M. (2014). What goes around comes around: Knowledge hiding, perceived motivational climate, and creativity. Academy of Management Journal, 57(1), 172-192. https://doi.org/10.5465/amj.2012.0122

Černe, M., Hernaus, T., Dysvik, A., \& Škerlavaj, M. (2017). The role of multilevel synergistic interplay among team mastery climate, knowledge hiding, and job characteristics in stimulating innovative work behavior. Human Resource Management Journal, 27(2), 281-299. https://doi.org/10.1111/1748-8583.12132

Connelly, C. E., Zweig, D., Webster, J., \& Trougakos, J. P. (2012). Knowledge hiding in organizations. Journal of Organizational Behavior, 33(1), 64-88. https://doi.org/10.1002/job.737

Connelly, C. E., \& Zweig, D. (2015). How perpetrators and targets construe knowledge hiding in organizations. European Journal of Work \& Organizational Psychology, 24(3), 479-489. https://doi.org/10.1080/1359432X.2014.931325 
Courpasson, D., \& Younes, D. (2018). Double or Quits: Understanding the links between secrecy and creativity in a project development process. Organization Studies, 39(2/3), 271-295. https://doi.org/10.1177/0170840617727780

Demirkasimoglu, N. (2016). Knowledge hiding in academia: Is personality a key factor? International Journal of Higher Education, 5(1), 128-140. https://doi.org/10.5430/ijhe. v5n $1 \mathrm{p} 128$

Fong, P. S. W., Men, C., Luo, J., \& Jia, R. (2018). Knowledge hiding and team creativity: The contingent role of task interdependence. Management Decision, 56(2), 329-343.

Fullwood, R., Rowley, J., \& Delbridge, R. (2013). Knowledge sharing amongst academics in UK universities. Journal of Knowledge Management, 17(1), 123-136. https://doi.org/10.1108/ 13673271311300831

Gray, P. H. (2001). The impact of knowledge repositories on power and control in the workplace. Information Technology \& People, 14(4), 368-384. https://doi.org/10.1108/ 09593840110411167

Hernaus, T., Cerne, M., Connelly, C., Poloski Vokic, N., \& Škerlavaj, M. (2019). Evasive knowledge hiding in academia: When competitive individuals are asked to collaborate. Journal of Knowledge Management, 23(4), 597-618. https://doi.org/10.1108/JKM-11$\underline{2017-0531}$

Kang, S. W. (2016). Knowledge withholding: psychological hindrance to the innovation diffusion within an organisation. Knowledge Management Research \& Practice, 14(1), 144-149. https://doi.org/10.1057/kmrp.2014.24

Kou, D. Y. (2002). The transaction cost perspective on knowledge sharing. (master's thesis), IShou University, Taiwan.

Kumar Jha, J., \& Varkkey, B. (2018). Are you a cistern or a channel? Exploring factors triggering knowledge-hiding behavior at the workplace: evidence from the Indian R\&D professionals. Journal of Knowledge Management, 22(4), 824-849. https://doi.org/10.1108/JKM-02-2017-0048

Labafi, S. (2017). Knowledge hiding as an obstacle of innovation in organizations a qualitative study of software industry / Ocultamiento del conocimiento como obstáculo para la innovación en las organizaciones: un estudio cualitativo de la industria del software. $A D$ minister(30), 131-148. https://doi.org/10.17230/ad-minister.30.7

Lin, T.-C., Wu, S., \& Lu, C.-T. (2012). Exploring the affect factors of knowledge sharing behavior: The relations model theory perspective. Expert Systems With Applications, 39(1), 751-764. https://doi.org/10.1016/j.eswa.2011.07.068

Lu, S., Au, W.-T., Jiang, F., Xie, X., \& Yam, P. (2013). Cooperativeness and competitiveness as two distinct constructs: Validating the cooperative and competitive personality scale in a social dilemma context. International Journal of Psychology, 48(6), 1135-1147. https://doi.org/10.1080/00207594.2012.743666 
Malik, O. F., Shahzad, A., Raziq, M. M., Khan, M. M., Yusaf, S., \& Khan, A. (2019). Perceptions of organizational politics, knowledge hiding, and employee creativity: The moderating role of professional commitment. Personality and Individual Differences, 142, 232-237. https://doi.org/10.1016/j.paid.2018.05.005

McKnight, D. H., \& Chervany, N. L. (2001). Trust and distrust definitions: One bite at a time. In Trust in Cyber-societies (pp. 27-54): Springer.

Peng, J., Wang, Z., \& Chen, X. (2019). Does self-serving leadership hinder team creativity? A moderated dual-path model. Journal of Business Ethics, 159(2), 419-433. https://doi.org/10.1007/s10551-018-3799-0

Perry, P. (2011). Concept analysis: Confidence/self-confidence. Paper presented at the Nursing Forum.

Qureshi, A. M. A., \& Evans, N. (2015). Deterrents to knowledge-sharing in the pharmaceutical industry: a case study. Journal of Knowledge Management, 19(2), 296-314. https://doi.org/10.1108/JKM-09-2014-0391

Raine, A., \& Uh, S. (2019). The selfishness questionnaire: Egocentric, adaptive, and pathological forms of selfishness. Journal of Personality Assessment, 101(5), 503-514. https://doi.org/10.1080/00223891.2018.1455692

Rhee, Y. W., \& Choi, J. N. (2017). Knowledge management behavior and individual creativity: Goal orientations as antecedents and in-group social status as moderating contingency. Journal of Organizational Behavior, 38(6), 813-832. https://doi.org/10.1002/job.2168

Rusk, J. D. (2018). Trust and distrust scale development: Operationalization and instrument validation. (doctorial dissertation), Kennesaw State University, Georgia.

Schaufeli, W. B. (2006). The balance of give and take: Toward a social exchange model of burnout. Revue internationale de psychologie sociale, 19(1), 75-119.

Serenko, A., \& Bontis, N. (2016). Understanding counterproductive knowledge behavior: Antecedents and consequences of intra-organizational knowledge hiding. Journal of Knowledge Management, 20(6), 1199-1224. https://doi.org/10.1108/JKM-05-2016-0203

Tamjidyamcholo, A., Baba, M. S. B., Tamjid, H., \& Gholipour, R. (2013). Information securityProfessional perceptions of knowledge-sharing intention under self-efficacy, trust, reciprocity, and shared-language. Computers \& Education, 68, 223-232. https://doi.org/10.1016/j.compedu.2013.05.010

Xiao, M., \& Cooke, F. L. (2019). Why and when knowledge hiding in the workplace is harmful: a review of the literature and directions for future research in the Chinese context. Asia Pacific Journal of Human Resources, 57(4), 470-502. https://doi.org/10.1111/1744$\underline{7941.12198}$ 


\section{Authors Biographies}

Kaiyu Yang, is a Ph.D. student in Knowledge Management and Innovation Management at the Institute for Knowledge and Innovation Southeast Asia (IKI-SEA), Bangkok University, Thailand. She is a faculty member in School of Foreign Languages at Baise University, China. Her research interest is in knowledge management.

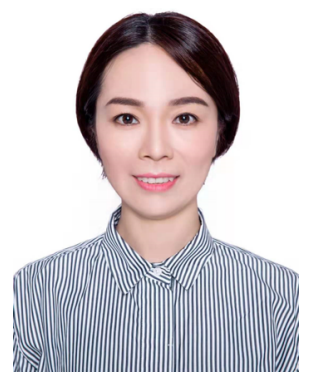

Vincent Ribiere, Ph.D. is an enthusiastic and creative International consultant and professor with a passion for helping organizations solving their organizational knowledge and innovation management challenges. He is the Founder and Managing Director of the Institute for Knowledge and Innovation Southeast Asia (IKI-SEA), a center of Excellence at Bangkok University as well as the Program Director of the Ph.D. in KM and Innovation Management. He delivers keynote speeches and workshops at various International Professional and Academic conferences and he is the Author of

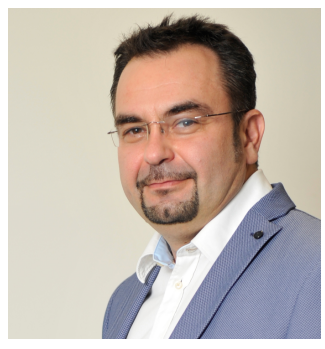
more than 80 publications. 